4 Ory HW, Conger SB, Naib Z, Taylor CW, Hatcher RA. Preliminary analysis of oral contraceptive use and risk of developing premalignant lesions of the uterine cervix. In: Garattini S, Berendes HW, eds. Pharm

5 Harris RWC. Brinton LA, Cowdell RH, et al Characteristics of women with dysplasia or carcinoma in situ of the cervix uteri. Br $\mathcal{J}$ Cancer 1980:42:359-69. Obstet Gy. Relationship of oral $1972 ; 40: 508-18$.

7 Boyce JG, Lu T, Nelson JH, Fruchter RG. Oral contraceptives and cervical carcinoma. Am $\mathcal{F}$ Obstet Gynecol 1977;128:761-6.

8 Peritz E, Ramcharan S, Frank S, Brown WL, Huang S, Ray R. The incidence of cervical cancer and duration of oral contraceptive use. Am $\mathcal{F}$ Epidemiol 1977; $106: 462-9$

9 Stern E, Forsythe AB, Youkeles L, Coffelt CF. Steroid contraceptive use and cervical dysplasia: increased risk of progression. Science 1977;196:1460-2.

10 Vessey MP, Lawless M, McPherson K, Yeates D. Neoplasia of the cervix uter and contraception: a possible adverse effect of the pill. Lancet 1983;ii:930-4 demiolow. Uterinecer vix. In: Schottenfeld D, Fraumeni JF, eds. Canc demiology and prevention. Philadelphia: W B Saunders, 1982:881-900. Aurelian L, Kessler 11, Rosenshein NB, Barbour G. Viruses and gynecologic cancers: herpesvirus protein (ICP 10 AG-4), a cervical tumour antigen that
fulfils the criteria for a marker of carcinogenicity. Cancer 1981;48:455-71.

13 Ory H, Naib Z, Conger SB, Hatcher RA, Tyler CW. Contraceptive choice and prevalence of cervical dysplasia and carcinoma in situ. Am $\mathcal{f}$ Obstet Gynecol previ:124:573-7.
14 Stern E, Coffelt CF. Contraceptives and dysplasia: higher rate for pill choosers. Science $1970 ; 169: 497-8$.

15 Hoover R, Bain C, Cole $P$, MacMahon B. Oral contraceptive use: association with frequency of hospitalization and chronic disease risk indicators. Am $\mathcal{f}$

16 Sobin LH, Thomas LB, Percy C, Henson DE, eds. A coded compendium of the international histological classification of tumours. Geneva: WHO, 1978

17 Breslow NE, Day NE. Statistical methods in cancer research. Vol 1. The analysis of case-control studies. Lyons: International Agency for Research on Cancer, 1980. Scientific publication No 32 .

18 Baker RJ, Nelder JA. The GLIM system. Release 3. Oxford: Numerical Algorithms Group, 1978.

19 Skegg DCG, Corwin PA, Paul C, Doll R. Importance of the male factor in cancer of the cervix. Lancet 1982;ii:581-3.

20 Winkelstein W Jr. Smoking and cancer of the uterine cervix hypothesis. Am $\mathrm{J}$ Epidemiol 1977;106:257-9.

21 Travanthan E, Layele $\mathrm{P}$, Webster LA, et al. Cigarette smoking and dysplasia and carcinoma in situ of the uterine cervix. $7 A M A 1983 ; 250: 499-502$.

22 Lyon JL, Gardner JW, West DW, Stanish WM, Hebertson RM. Smoking and carcinoma in situ of the uterine cervix. Am $\mathrm{f}$ Public Health

Andolsek L Kovacic J, Kozuh M, Litt B. Oral contraceptives and cancer. Lancet 1983;ii: 1310 .

(Accepted 12 December 1984)

\title{
Counselling problem drinkers in medical wards: a controlled study
}

\author{
JONATHAN CHICK, GEOFFREY LLOYD, EVELYN CROMBIE
}

\begin{abstract}
Seven hundred and thirty one men admitted to medical wards were interviewed to identify problem drinkers who had not received previous treatment for alcoholism and who had some social support. One hundred and sixty one met the diagnostic criteria; 156 agreed to a follow up interview and were allocated to one of two groups. One group received a session of counselling about their drinking habits from a nurse while the other received only routine medical care. Both groups reported a reduction in alcohol consumption when interviewed 12 months later, but the counselled group had a significantly better outcome than the control group.
\end{abstract}

It is concluded that systematic screening for alcohol consumption and related problems should become a routine part of medical assessment and that advice on drinking habits is effective if given before irreversible physical or psychosocial problems have developed.

\section{Introduction}

Treatment of patients with alcohol problems is often unsatisfactory because many of them have developed advanced physical, psychiatric, or social complications before they present for medical help. Earlier detection has been recommended on the assumption that intervention will be more effective at an earlier stage in the illness, ${ }^{1}$ but this has not yet been widely tested. Problems related to alcohol are common among inpatients in general hospitals,,$^{23}$ and people subsequently identified as alcoholics have an excess of medical admissions for a wide range of conditions. ${ }^{4}$ The extent of the Alcohol Problems Clinic, Royal Edinburgh Hospital, Edinburgh
EH10 5HD

JONATHAN CHICK, MRCP, MRCPSYCH, consultant psychiatrist

Royal Infirmary, Edinburgh EH3 9YW

GEOFFREY LLOYD, MD, FRCPED, consultant psychiatrist

EVELYN CROMBIE, RGN, RMN, research nurse

Correspondence to: Dr Jonathan Chick. problem, however, requires that the ideal treatment should be brief and readily available.

We report a study carried out in medical wards to determine the effectiveness of brief intervention in problem drinkers who had not received previous treatment and had at least some social support, which is an important influence on the outcome of treatment of alcoholism. ${ }^{5}$

\section{Patients and methods}

SCREENING

We studied a consecutive series of men aged 18-65 admitted for at least 48 hours to one of four male medical wards covering a wide range of specialties. The study was confined to men because the first six months of screening indicated a very low proportion of newly identified cases among women. ${ }^{6}$

Patients were excluded at the outset if they were of no fixed abode, their mental state precluded a reliable history, they were terminally ill, or they had already been referred to the department of psychiatry. A structured interview of proved interrater reliability was then given by a nurse with experience in treating alcoholism; this interview covered consumption, dependence, problems related to alcohol, recent and distant medical history, and social background Patients were identified as problem drinkers if they acquired two or more points according to the criteria listed in the figure.

Patients were included in the study only if they met at least two of the following criteria: currently employed or employed for six of the past 12 months; married; had a "confidant" or close friend; or lived with at least one other person.

\section{RANDOMISATION AND INTERVENTION}

Patients who satisfied the above criteria were asked to participate in the study, which, they were told, was concerned with the relation between their health and drinking habits; they were also informed that they would be interviewed again 12 months later. Allocation was made to one of two groups: control and treatment. A compromise had to be made to the traditional method of random allocation of patients in a clinical trial. We wished to avoid a control patient being in the bed adjacent to a patient in the treatment group. Each ward therefore alternated every two or three months between being a source of controls and patients in the treatment group. This had the disadvantage that before the assessment interview began the nurse knew whether the patient, if recruited to the study, would be 
in the treatment group or not, but she endeavoured to keep the assessment procedure standardised. Patients in the treatment group received further counselling from the nurse. The session lasted up to 60 minutes, during which the nurse gave the patient a specially prepared booklet and engaged him in a discussion on his lifestyle and health, which helped him to weigh up the drawbacks of his pattern of drinking and to come to a decision about his future consumption. The objective was to help the patient towards problem free drinking, though abstinence was the agreed goal for some. Controls received no advice; no comment was made about the content of the screening interview. The physician in charge, however, may have advised the patient to modify his alcohol consumption, according to his normal practice. Mean cell volume and $\gamma$-glutamyltranspeptidase activity were measured in all cases as laboratory markers of alcohol consumption.

\section{FOLLOW UP}

Patients were approached again after one year. The interviewer was a senior nurse with experience of interviewing about alcoholism. He was unaware of the design of the study. The follow up interview included questions about general health and experience of problems related to alcohol (figure) in the 12 months since leaving hospital, and questions about alcohol consumption were repeated. Blood was

\section{Consumption}

Over 14 units* in a day on 10 or more occasions in past year

Over 50 units in typical week

Over 12 units in 24 hours in typical week

\section{Problems related to alcohol \\ Current medical problems}

Present illness potentially related to alcohol

Present illness definitely related to alcohol

Weight problem due to alcohol

\section{Medical problems in past two years}

Peptic ulcer aggravated by drinking

Liver disease due to alcohol

Accident due to drinking

\section{Social problems in past two years}

Antisocial behaviour

Problems at work (including absence)

Domestic arguments

Violence

Family rupture (threatened or actual)

Financial

Police

Dependence on alcohol in past two years

Difficulty in reducing consumption

Restlessness without alcohol

Tremor (over one day a week)

Morning relief drinking (over one day a week)

Hallucinations

Withdrawal seizure

Criteria for inclusion as a problem drinker. Patients scored one point for presence of any variable except for $\dagger$ presence of illness definitely due to alcohol, which scored two points.

*1 unit $=57 \mathrm{~g} \mathrm{(1} \mathrm{oz)} \mathrm{of} 40 \%$ (by volume) spirits; $13.7 \mathrm{ml}$ (half pint) of $3.6 \%$ (by volume) beer; one glass of wine, etc-that is, roughly, $8 \mathrm{~g}$ ethanol. taken to measure mean cell volume and $Y$-glutamyltranspeptidase activity.

During the year the patient might have received treatment for his alcohol problem from his general practitioner, from a hospital doctor, or at a treatment agency listed in the advice booklet. The interviewer did not ask about this as the information might have biased his observations.

\section{DEFINING OUTCOME CATEGORIES}

Patients were thought to be definitely improved if they reported no problems related to alcohol in the year to follow up. If the patient reported no problems at either interview he was considered to be improved if his consumption had fallen by $50 \%$ or more. In both cases improvement had to be supported by results of blood tests or a relative's report. If these criteria were not satisfied patients were regarded as not definitely improved.

$\gamma$-Glutamyltranspeptidase activity supported self reported improvement if it was $40 \mathrm{IU} / \mathrm{l}$ or below at intake and remained at that concentration, or if it had been above $40 \mathrm{IU} / 1$ and subsequently fell by at least $20^{\circ}{ }_{0}$. Mean cell volume supported self reported improvement if it was $96 \mathrm{fl}$ or below at intake and remained at that level, or if it had been above $96 \mathrm{fl}$ and subsequently fell by at least $2 \mathrm{fl}$.

\section{Results}

A total of 731 men eligible for inclusion were admitted during the study, of whom 161 met our diagnostic criteria. One hundred and fifty six agreed to a follow up interview, and 78 were allocated to each of the two groups. Control and treatment groups did not differ with regard to age, marital state, level of social support, occupational state, medical diagnosis, mean alcohol consumption in the week before admission, or mean cell volume and $\gamma$-glutamyltranspeptidase activity (table I). Symptoms of physical dependence were uncommon and did not differ between the two groups. The groups differed however, with regard to the total mean problem score, which was higher in the group given counselling than in the controls $(p=0.014)$ When patients were divided into those who did and those who did not admit to problems related to alcohol at intake the two groups were still matched on medical, sociodemographic, and dependence items and blood tests.

We interviewed 133 patients after one year. Data on $\gamma$-glutamyltranspeptidase activity and mean cell volume were available at both interviews in 124 cases. Three patients had died during the intervening period, and 20 could not be contacted or refused to be seen. This indicated poor outcome ${ }^{7}$ and applied to more controls than patients given counselling.

Table I shows measures of outcome, from which it can be seen that both groups significantly reduced their mean weekly alcohol consumption. Patients who had been counselled did not reduce their consumption more than the controls, but $44(64 \%)$ of these patients claimed that they had reduced their consumption by at least $50^{\circ} \%$, compared with $31(48 \%)$ of the controls $(p=0.07)$. The patients given counselling showed significant improvements in their score for problems related to alcohol and $\gamma$-glutamyltranspeptidase activity. Because they had a higher mean problem score at intake, however, the change in problem score was calculated as a percentage of the initial value. This showed a greater mean fall $(41 \%)$ for the patients given counselling than the controls $(14 \%)(p=0.03)$. At intake $23(30 \%)$ of the patients given counselling and $30\left(39^{\circ} \%\right)$ of the controls did not acknowledge any problems, whereas at follow up the numbers were $40(58 \%)$ and $33(52 \%)$, respectively.

A significant difference between the groups was found when global categories of outcome were examined. Of the 124 interviewed for whom complete blood tests were available, $34(52 \%)$ of those given counselling and $20(34 \%)$ of the controls were categorised as definitely improved $(\mathrm{p}=0.038)$ (table II). Thirteen $\left(19^{\circ} \%\right)$ of the patients given

TABLE I-Mean values (SEM) at intake and follow up for patients followed up at one year

\begin{tabular}{|c|c|c|c|c|c|c|c|c|}
\hline & \multicolumn{2}{|c|}{ Consumption in past week (units) } & \multicolumn{2}{|c|}{ Problems related to alcohol } & \multicolumn{2}{|c|}{ Mean cell volume (f) } & \multicolumn{2}{|c|}{$\gamma$-Glutamyltranspeptidase activity (IU/l) } \\
\hline & Intake & Follow up & Intake & Follow up & Intake & Follow up & Intake & Follow up \\
\hline $\begin{array}{l}\text { Patients given counselling } \\
\text { Controls }\end{array}$ & \multicolumn{2}{|c|}{ 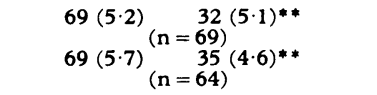 } & \multicolumn{2}{|c|}{$\begin{array}{c}2 \cdot 4(0 \cdot 3)(n=69) \\
1 \cdot 4(0 \cdot 2) \underset{(n=6 \cdot 2)^{* *}}{(1 \cdot 2}(0 \cdot 2) \\
(n=64)\end{array}$} & \multicolumn{2}{|c|}{ 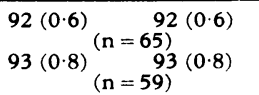 } & \multicolumn{2}{|c|}{ 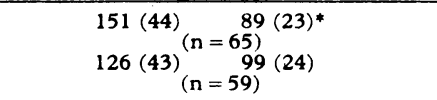 } \\
\hline
\end{tabular}

$* p<0.05, * * p<0.001$ compared with values at intake. 
TABLE II-O Otcome after one year

\begin{tabular}{lcccccc}
\hline & Dead $\begin{array}{c}\text { Refused } \\
\text { or no } \\
\text { contact }\end{array}$ & $\begin{array}{c}\text { Blood } \\
\text { tests } \\
\text { incomplcte }\end{array}$ & $\begin{array}{c}\text { Definitely } \\
\text { improved }\end{array}$ & $\begin{array}{c}\text { Not definitely } \\
\text { improved }\end{array}$ \\
\hline $\begin{array}{l}\text { Patients given } \\
\text { counselling }(n=78)\end{array}$ & 1 & 8 & 4 & $34^{*}$ & $31^{*}$ \\
Controls $(n=78)$ & 2 & 12 & 5 & 20 & 39 \\
\hline
\end{tabular}

*Patients given counselling $r$ controls: $\%^{2}=4 \cdot 26, p=0.038$

counselling and $15\left(23^{\circ}{ }_{0}\right)$ of the controls were admitted to hospital during the follow up period; four $\left(6^{\prime}{ }_{0}\right)$ and $11\left(17^{\circ}{ }_{1}\right)$, respectively, were admitted for eight days or more.

\section{Discussion}

Many patients showed a substantial improvement during the 12 months after the index admission to hospital. The experience of being ill, advice from various doctors treating them, and increases in the price of alcohol " may all have had a beneficial effect. There may also have been a "regression to the mean" effect: some patients were admitted with illnesses related to alcohol after a period of heavy drinking, and it is to be expected that at an arbitrary point in the future the consumption and associated problems of such patients would be reduced. Nevertheless, those who received additional counselling achieved a significantly greater improvement than those who received only routine medical care.

In defining outcome we gave precedence to improvements in self reported problems related to alcohol over improvements in self reported consumption because we believe that it is harder for a man to prevaricate about whether he has lost a job through drinking, for example, than about how much he drank in the previous week or in a typical week. Furthermore, our strategy of treatment was aimed at helping men achieve problem free drinking and not necessarily complete abstinence.

Our groups were not matched for the number of alcohol related problems at intake, though they were matched on every other variable at intake that we measured. We believe that this lack of matching can only have occurred by chance. In view of the difference in alcohol related problems we specified definite improvement as complete freedom from problems at follow up. This might have weighted our analysis against finding an effect of counselling because it would be harder for patients with several problems related to alcohol (of whom there were more in the counselling group) to become completely free of them than for patients with few problems.

The effectiveness of treatment for established alcoholics continues to be a matter of debate. A controlled study of intervention in early cases has yielded promising results ${ }^{9}$; even self help booklets, such as Drinking Problems: Information and Advice for the Individual, Family and Friends, ${ }^{10}$ have proved successful. ${ }^{11}$ The effect of treatment may well persist if brief intervention is repeated at intervals. ${ }^{9}$ Our study shows how important early detection is, and our results are sufficiently encouraging for us to recommend that similar studies should be conducted in other general hospitals with inpatients or outpatients. Patients may be especially receptive to counselling when recovering from a medical illness. Screening for alcohol problems should become a routine part of nursing assessment and the medical history so that advice can be given before irreversible physical or psychosocial problems have developed.

We thank the patients for their cooperation; the medical and nursing staff of the Royal Infirmary; the Scottish Home and Health Department, which funded the study; and Sally Anderson, Valerie Walker, and especially Terry Anderson for his perseverance in the follow up.

\section{References}

1 Advisory Committee on Alcoholism. The pattern and range of services for problem drinkers. London: HMSO, 1978 .
arman CMB, Kellett JM. Alcoholism in the general hospital. Br Med f 1979 ; Jarman $C M$

Quinn MA, Johnston RV. Alcohol problems in acute male medical admissions. Health Bull (Edinb) 1976;34:253-6.

$4 \mathrm{Kolb} \mathrm{D}$, Gunderson EKE. Medical histories of problem drinkers during their first twelve years of naval service. F Stud Alcohol 1983;44:84-94.

5 Costello RM. Alcoholism treatment and evaluation: slicing the outcome variance pie. In: Edwards G, Grant $M$, eds. Alcoholism treatment in transition. London Croom Helm, 1980:113-27

6 Lloyd G, Chick J, Crombie E. Screening for problem drinkers among medical in-patients. Drug Alcohol Depend 1982;10:355-9.

7 Moos R, Bliss F. Difficulty of follow-up and outcome of alcoholism treatment.

F Stud Alcohol 1978;39:473-90.
8 Kendell RE, de Roumanie M, Ritson EB. Effect of economic changes on Scottish drinking habits. Br $\mathcal{F}$ Addict 1983;78:365-80.

9 Kristensson $\mathrm{H}$, Ohlin $\mathrm{H}$, Hultén-Nosslin MB, Trell E, Hood B. Identification and intervention of heavy drinking in middle-aged men: results and follow-up of $24-60$ months of long-term study with randomised controls. Alcoholism 10 Chick J, Chick J. Drinking problems: information and advice for the individual, family and friends. Edinburgh and London: Churchill Livingstone, 1984 11 Miller WR, Taylor CA. Relative effectiveness of bibliotherapy, individual and group self-control training in the treatment of problem drinkers. Addict Behav 1980;5:13-24.

(Accepted 18 January 1985)

\section{Paecilomyces varioti pneumonia complicating hairy cell leukaemia}

Infection is the major cause of morbidity and death in patients with hair cell leukaemia.' Aspergillosis and candidiasis are common mycotic infections in such patients, and histoplasmosis and cryptococcosis have been described," but pneumonia due to Paecilomyces varioti has not been reported. We report on a patient with hairy cell leukaemia who developed such pneumonia.

\section{Case report}

A 64 year old woman with hairy cell leukaemia presented with a history of cough accompanied by small amounts of greyish sputum of five weeks' duration. Hairy cell leukaemia had been diagnosed six years previously when she presented with Gram negative septicaemia. Her white cell count then had been $2.7 \times 10^{9} / 1$ with $90^{\prime \prime}$, hairy cells in the peripheral blood. Aspiration of bone marrow and trcphine biopsy had confirmed the diagnosis. Initial treatment with steroids, chlorambucil, and cyclophosphamide had been followed by splenectomy. Recurrent attacks of pneumonia had occurred over the next few years but responded to treatment with antibiotics. Her most recent infection had been treated with erythromycin and oxytetracycline. Despite this she had developed fever $\left(37 \cdot 8^{\circ} \mathrm{C}\right)$, shortness of breath, and left pleuritic pain

On examination she was distressed and dyspnoeic with a blood pressure of $140 / 80 \mathrm{~mm} \mathrm{Hg}$ and a pulse rate of 98 beats $/ \mathrm{min}$. Further examination showed signs of pneumonia of the left lower lobe but no other abnormality. Haemoglobin concentration was $10.5 \mathrm{~g} / \mathrm{dl}$ and white cell count $13.8 \times 10^{9} / 1$ with $1 \%$, neutrophils and $99 \%$ lymphocytes, of which $10 \%$ were hairy cells. Platelet count was $31 \times 10^{9} / 1$, and biochemical investigations gave normal results. A chest radiograph showed shadowing at the left base with loss of diaphragmatic and cardiac borders. Cultures of sputum, urine, and blood yielded negative results. Empirical treatment with ceftazidime $2 \mathrm{~g}$ eight hourly and vancomycin $500 \mathrm{mg}$ eight hourly with infusions of granulocytes produced little clinical response. Bronchoscopy performed 10 days after admission showed copious secretions in the bronchial tree. Films of bronchial lavage fluid from the left lower lobe, treated by Grocott's silver method, showed septate branching hyphae. Examination of these preparations showed phialides and conidia resembling a Paecilomyces species. Definitive diagnosis was achieved after five days' incubation at $37 \mathrm{C}$ when granular yellow brown or khaki colonies appeared. Cultures stained by lactophenol cotton blue showed chains of unicellular conidia arising from basally swollen phialides characteristic of Puecilomyces species. Amphotericin B $60 \mathrm{mg}$ daily by infusion for six hours was added to the treatment. Within three days she had improved considerably; her fever settled and over six weeks radiographs of her chest cleared. She was discharged and remained well. 